\title{
Commentary: Just because we can doesn't mean we should
}

\author{
Jennifer Nishimura, MD, and Nahush A. Mokadam, MD
}

From the Division of Cardiac Surgery, Department of Surgery, The Ohio State University Wexner Medical Center, Columbus, Ohio.

Disclosures: Dr Mokadam is a consultant and investigator for Abbott, Medtronic, and SynCardia. Dr Nishimura has nothing to disclose with regard to commercial support.

Received for publication July 12, 2019; accepted for publication July 12, 2019; available ahead of print Aug 14, 2019.

Address for reprints: Nahush A. Mokadam, MD, Division of Cardiac Surgery, The Ohio State University Wexner Medical Center, N-825 Doan Hall, 410 West 10th Ave, Columbus, OH 43210 (E-mail: Nahush.Mokadam@ osumc.edu).

J Thorac Cardiovasc Surg 2020;159:2324-5

$0022-5223 / \$ 36.00$

Copyright (c) 2019 by The American Association for Thoracic Surgery

https://doi.org/10.1016/j.jtcvs.2019.07.049

Burnout has received national attention in the media and has been recognized as an under-reported problem in health care. In fact, physicians are more likely to have symptoms of burnout than other working US adults $(37.9 \%$ vs $27.8 \%)^{1}$ A recent search of PubMed with the term "burnout" resulted in almost 15,000 citations. ${ }^{2}$ Although most citations were related to physicians, there were also interspersed publications for medical students, nurses, physician assistants, social workers, and others. The estimated costs related to physician turnover and reduced clinical hours attributed to burnout each year in the United States was approximately 4.6 billion dollars. ${ }^{3}$ The emerging recognition of this facet of health care has certainly garnered significant focus by many; at the same time, we still are at least partially to blame.

In this issue of The Journal of Thoracic and Cardiovascular Surgery, Axtell and colleagues present a wellcrafted, single-institution retrospective study evaluating outcomes and costs after elective cardiac surgery on the basis of operating start time. ${ }^{4}$ In the study no significant difference in 30-day mortality, composite morbidity, intensive care unit stay, or total hospital cost for cases with incision time after 3 PM were reported compared with earlier start times. These results speak to the high quality and function of cardiac surgery teams, commitment, and their resilience there, and we suspect at many other institutions. Furthermore, this article highlights a topic that has become an area of interest, value-based health care, which measures patient outcomes and cost of delivering these outcomes. ${ }^{5}$ Their study showed that there were no significant differences in costs and outcomes. The findings of this study might provide patients with some sense of reassurance for their safety. Importantly, the study was not intended to encourage operating after hours while team morale, burnout, and staff retention were acknowledged, but not assessed.

Times are getting tough. The complexity of cases and patients, "paperwork," and demands of delivering safe and

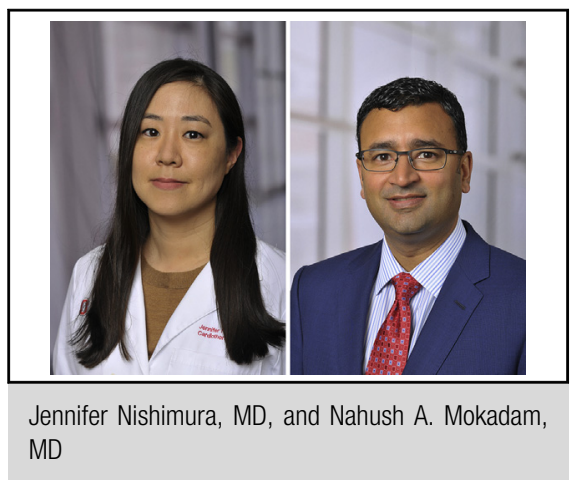

\section{Central Message}

Although excellent outcomes can be achieved by high-functioning cardiac surgery teams at all hours, consideration for team morale, burnout, and retention are important to prioritize as well.

See Article page 2314.

effective health care are likely to increase. We must manage all of this and aim to achieve perfect quality metrics and patient satisfaction scores. Chief executive officers of leading health care organizations have recognized that burnout is a problem and some have developed strategies to address it. ${ }^{6}$ However, we cannot rely solely on administration to solve this problem. Cardiac surgeons must be leaders of their team and make decisions or system changes that do not compromise patient care, but also consider longevity and wellness of their coworkers, so that they can take care of their patient today, and also be able to take care of the next patient tomorrow and after. This is called distributive justice in the realm of ethics, and cannot be ignored.

We must empower ourselves. Resist the urge to feel guilt when we try to address wellness for others on our team, or for ourselves. The challenges that we will face in cardiac surgery will be better matched by a team that does not have to rely on their resilience to thrive. Just because we can do something well, does not mean we always should.

\section{References}

1. Shanafelt TD, Boone S, Tan L, Dyrbye LN, Sotile W, Satele D, et al. Burnout and satisfaction with work-life balance among US physicians relative to the general US population. Arch Intern Med. 2012;172:1377-85.

2. NCBI. PubMed.com. Available at: www.pubmed.com. Accessed July 3, 2019.

3. Han S, Shanafelt TD, Sinsky CA, Awad KM, Dyrbye LN, Fiscus LC, et al. Estimating the attributable cost of physician burnout in the United States. Ann Intern Med. 2019;170:784-90. 
4. Axtell AL, Moonsamy P, Melnitchouk S, Jassar AS, Villavicencio MA, D'alessandro da, et al. Starting elective cardiac surgery after 3 pm does not impact patient morbidity, mortality, or hospital costs. J Thorac Cardiovasc Surg. 2020; 159:2314-21.e2.
5. NEJM Catalyst. What is value-based health care? Available at: https://catalyst nejm.org/what-is-value-based-healthcare. Accessed July 2, 2019.

6. Ellison EM. Beyond the economics of burnout. Ann Intern Med. 2019;170 807-8. 